\title{
集肤式电伴热在 DN600 原油管线连接项目的应用研究
}

\section{Application of Skin Tracing in DN600 Crude Oil Pipeline Connection Project 吕哲颖}

Zheying Lv

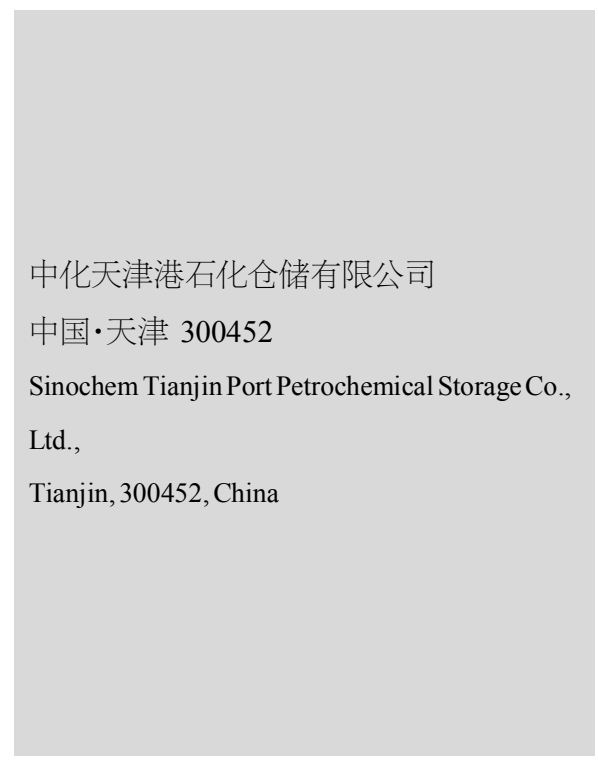

【摘要】为进一步提升企业原油接卸能力,利用公共管廊架,敷设一条 DN600 原油管线长 约 $3.6 \mathrm{~km}$ 。管线操作压力 $0.8 \mathrm{MPa}$, 操作温度 $60^{\circ} \mathrm{C}$, 全线采用集肤效应电伴热对管线进行保 温伴热。文章论证了此种加热技术在石化管道伴热的可行性及在其应用中具有效率高、使 用广泛等优点

【Abstract】In order to further improve the crude oil receiving and unloading capacity of the enterprise, a DN600 crude oil pipeline is laid with a length of about 3.6km using a public pipe rack. The operating pressure of the pipeline is $0.8 \mathrm{MPa}$, and the operating temperature is $60^{\circ} \mathrm{C}$. Skin effect electric heat tracing is adopted for heat preservation and heat tracing of the pipeline. This paper demonstrates the feasibility of this heating technology in petrochemical pipeline heat tracing and its advantages of high efficiency and wide application.

【关键词】石化管线; 电伴热; 集肤效应; 箱式变电站; 维持温度

【Keywords】petrochemical pipeline; electric heat tracing; skin effect; box substation; maintaining temperature

【DOI】10.36012/etr.v2i3.1419

\section{1 传统管道电伴热特点}

\section{1 自限温伴热带}

自限温伴热带的热量输出随温度的变化而变化。最高温 度: $150^{\circ} \mathrm{C}$, 单根回路最大长度: $100 \mathrm{~m}$ 。特点: 温度自动调节; 安 装时可随意裁剪; 适合复杂管线、储罐系统。

\section{2 并联恒功率伴热带}

靠发热丝发热。最高温度: $150^{\circ} \mathrm{C}$, 单根回路最大长度: $300 \mathrm{~m}$ 。特点: 功率恒定, 稳定发热; 安装时可随意裁剪; 适合安 装于复杂管线、储罐系统。

\section{3 串联恒功率伴热带}

靠自身电阻发热, 安装时不可随意裁剪。最高温度: $120^{\circ} \mathrm{C}$, 单根回路最大长度: $3600 \mathrm{~m}$ 。特点: 功率恒定, 稳定发热; 伴热距离长; 适合安装于装置区之间相连的管道、储罐系统。

\section{4 传统电伴热带的缺点}

管道维温距离较短, 发热效率低, 热传导效率低, 使用寿 命较短, 易受外力导致损坏, 维护维修困难等。传统电伴热带 直接加热, 因为没有防护层, 所以腐蚀严重, 影响生产效率 ${ }^{[1]}$ 。

\section{2 集肤式电伴热特点}

\section{1 集肤效应技术原理}

当电流经过导体时,受到集肤效应的影响,电流会集中在 导体的表面, 如果把 $\mathrm{T}$ 缆穿入热管中, 受到邻近效应的影响, 电流会集中在热管的管内壁部分,这样管外壁不会有电流, 确 保系统安全 ${ }^{[2]}$ 。导体和管的横切面如图 1 所示。
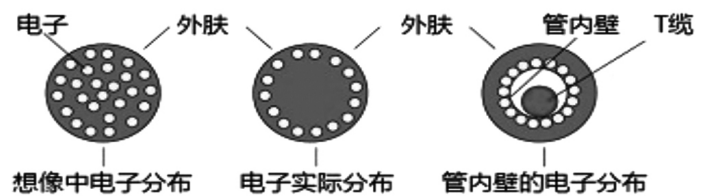

图 1 导体和管的横切面

传统电伴热带敷设在管道外壁, 热量通过热辐射的方式 传递给管道, 热损失严重, 热效率很低, 伴热带与管道温度差 高达 $30^{\circ} \mathrm{C}$ 甚至以上;集肤效应伴热系统, 热管焊接在管道外 壁，热量直接通过传递的方式输送给管道，大大提高了热效 率, 热管与管道温度差仅为 $5^{\circ} \mathrm{C}$ 。

集肤效应电伴热系统适用于各类复杂和长输管道、管网 


\section{实验与研究 Experiments and Research}

的介质维温、加热和解凝。根据其原理, 集肤效应电伴热系统 利用一种坚固的、厚管壁的碳钢“热管”对储运储罐和管道介 质进行维温、加热, 实现革命性的高能效的解决方案 ${ }^{[3]}$ 。

集肤效应电伴热系统最大的优点是一个电源点可以为 $25 \mathrm{~km}$ 输油管道进行维温, 减少了对庞大供电系统的需要; 利 用公共管廊，管廊四周无取电点，并且管线敷设有架空管 道、涵洞管道。经过分析原油管线电伴热采用集肤效应电伴 热技术, 将铠装发热元件直接焊接在工艺管道上, 实现介质 管道预热、维温、防凝目的。集肤效应电伴热系统示意图如 图 2 所示。

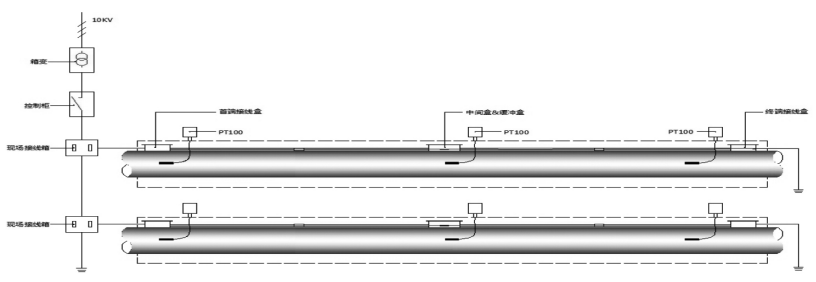

图 2 系统示意图

\section{2 工作流程}

热管与被伴热介质管,通过焊接的方式连接,将热管与介 质管形成一个整体; 热管发出的热量, 直接传递到介质管上, 而不是像传统电伴热带通过热辐射传热，热辐射传热只能够 将介质管的局部发热，直接导热首先热的是介质管道的管壁 (见图 3)。

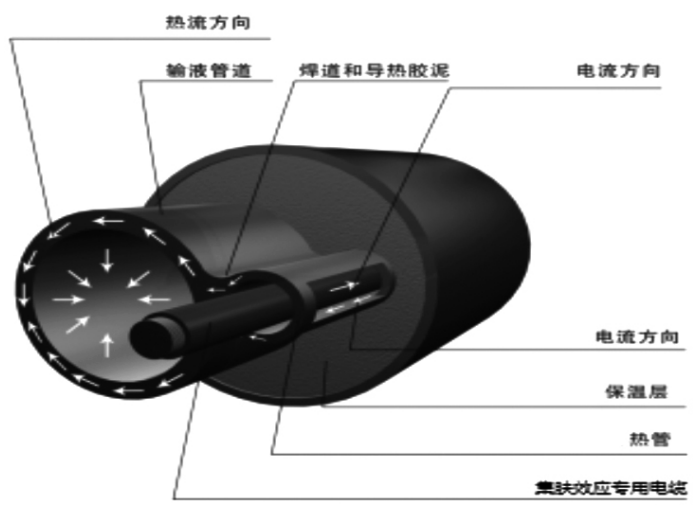

图 3 集肤效应电伴热工作流程

\section{3 特点分析}

根据管径的大小、伴热温度的高低,集肤效应电伴热分为 单管、双管和三管伴热。管壁集肤层导电截面减小,交流阻抗 显著增加,在相同的电流作用下,管线得到较大的加热功率, 经传导使输油管线升温。

(1)功能全面: 具有伴热、加热、防冻、解凝等综合功能, 安 全可靠、无排放、节能环保。(2)半热距离长:一个电源点可对长 达 $25 \mathrm{~km}$ 的管线进行伴热、加热, 减少电源点。(3)功率大: 最高
功率可达 $160 \mathrm{~W} / \mathrm{m}$, 最高维持温度可达 $250^{\circ} \mathrm{C}$ 。(4)热效率高: 通 过焊点和导热胶泥进行热传导, 发热管与管道温差 $5^{\circ} \mathrm{C}$ 左右, 用最短时间即可对管道进行预热和加热。(5)维护方便: 相对传 统伴热方式,如果更换伴热线, 需将管线保温全部拆开, 费时 费力, 集肤效应系统仅需打开几块保温, 将废旧的 $\mathrm{T}$ 缆拉出 来, 再穿入新 $\mathrm{T}$ 缆即可, 省时省力。

\section{3 控制方案说明}

根据伴热管线长度 $3.6 \mathrm{~km}$, 维持温度 $60^{\circ} \mathrm{C}$, 计算出集肤效 应伴热的电功率。

新建一座箱式变电台, 采用电伴热变压器 SR526/10kV, 即 $10 \mathrm{kV}$ 变 $1.5 \mathrm{kV}$ 一台; KYN28A 额定电压 $10 \mathrm{kV}$ 额定电流 $630 \mathrm{~A}$ 进线柜一台, $\mathrm{KYN} 28 \mathrm{~A}$ 额定电压 $1.5 \mathrm{kV}$ 、额定电流 $250 \mathrm{~A}$ 馈线柜二台; 保护装置采用综合保护器包括: 电流速断、过流、 过电压保护; 集肤效应维温加热系统, 采用电子温控仪, 利 用现场测温传感器感知容器表面温度及介质温度, 实现多 回路动态控制、智能通断、分布加热, 达到最佳节能效果。传 感器每隔 600 秒就将这些数据发送给集肤效应电伴热系统 控制中心, 经过分析集肤效应电伴热系统制定出最佳的维 温解决方案。

DN600mm 管网使用集肤效应电伴热节能效果分析: $\mathrm{DN} 600 \mathrm{~mm}$ 管网投入运行后, 在环境温度 $12 \sim 17^{\circ} \mathrm{C}$, 同时对集 肤效应电伴热和恒功率电伴热进行了 $3 \mathrm{~d}$ 不间断测试, 将 $\mathrm{DN} 600 \mathrm{~mm}$ 管网温度提升至 $30^{\circ} \mathrm{C}$, 集肤效应电伴热升温快, 耗 电量平均 $0.08 \mathrm{kWh} / \mathrm{m}$, 恒功率电伴热耗电量 $0.14 \mathrm{kWh} / \mathrm{m}$, 集肤 效应伴热节电效果显著。

\section{4 结语}

在中国北方寒冷季节, 石化管线采用集肤效应电伴热能 为各种钢质输送管道提供伴热, 适用于隧道及管廊架空敷设 管网。外集肤效应电伴热系统的耐热集肤电缆在伴热热管内, 伴热热管与工艺管道焊在一起, 外面加有保温层和保护外壳, 加热效率显著提高, 节省电源取电点, 抗腐蚀、抗损坏、节能效 果明显,在较长伴热管线上推广使用。

\section{参考文献}

[1]常瑞增.集肤效应电伴热替代蒸汽伴热的应用 $[\mathrm{J}]$.资源节约与 环保,2011(2):36-38

[2]王泉.输油管线的同步优化设计[J].化工设计通讯,2017,43(7): 34

[3]王照亮,梁金国,王弥康.电伴热采油和输油工程设计 [J].石油 大学学报(自然科学版),1998(2):38-40+115. 